\title{
La tesis como artículo científico
}

\author{
The thesis as scientific paper
}

\author{
Raúl Ishiyama Cervantes ${ }^{a}$
}

En las universidades y los institutos superiores de educación se sustentan tesis, las que después de ser aprobadas la mayoría de las veces el destino final es el estante de la biblioteca central. La tesis es una investigación sobre un tema en la que se muestran nuevos conocimientos producto de determinadas interrogantes que se planteó el autor. En nuestro sistema, la ley universitaria permite que cada universidad tenga su propio esquema y cada facultad la propia. El formato está atomizado.

La razón de este artículo es sobre las investigaciones experimentales o cuantitativas. En el post grado sobre la tesis generalmente se dictan hasta tres cursos: Tesis I, Tesis II y Seminario de Tesis. La mayoría de estos son teóricos, por lo que no le es de mucha utilidad al graduando; los pocos que se gradúan tuvieron que hacer un esfuerzo para cumplir con el reglamento.

La nueva ley universitaria dice: "Artículo 45. Obtención de grados y títulos. La obtención de grados y títulos se realiza de acuerdo a las exigencias académicas que cada universidad establezca en sus respectivas normas internas. Los requisitos mínimos son los siguientes: 45.2 Título Profesional: requiere del grado de Bachiller y la aprobación de una tesis o trabajo de suficiencia profesional. Las universidades acreditadas pueden establecer modalidades adicionales a estas últimas. El título profesional sólo se puede obtener en la universidad en la cual se haya obtenido el grado de bachiller" (1).

No establece un formato universal para todas las universidades, la sustenta con "...se realiza de acuerdo a las exigencias académicas que cada universidad establezca en sus respectivas normas internas...", esto determina que cada institución tenga su propio reglamento.

En el pregrado algunos docentes del curso Metodología de la Investigación complican la formación de los potenciales investigadores con cursos detallistas y memorísticos, haciendo, de algo sencillo, un aprendizaje complicado sin prácticas. La práctica hace mejor a la persona, así como su capacidad profesional. No enseñan cómo diseñar proyectos sencillos ni a encontrar temas originales que se encuentran en cantidades en el ambiente y en la literatura científica ${ }^{(2)}$. Exigen que el proyecto sea diseñado con una serie de planteamientos complicados como si fuera a perdurar eternamente. El proyecto es como el plano de una casa, sencillo; a medida que se va construyendo el diseño se puede ir modificando, cuando se tiene la casa concluida el plano se archiva. Similar en la investigación, escrita la tesis el proyecto ya no tiene razón de ser, sirvió para desarrollar la investigación en forma ordenada.

Sobre el contenido de una tesis, el autor es el experto en su tema, no hay nadie que la conozca mejor que él, porque él la diseño, él la realizó y él la escribió con el apoyo de su asesor. Los miembros del jurado pueden ser expertos en el tema relacionado con el contenido del trabajo gracias a sus investigaciones publicadas, por lo que podrán hacer observaciones, preguntas sobre la forma, aclaración a las dudas sobre la veracidad de lo presentado, así como en donde encuentren discrepancias. Salvo que determinen que es plagio.

Aventurando un cálculo.

Si anualmente en una universidad se gradúan 100 personas, con 10 facultades hace un total de 1000 trabajos de investigación. Considerando el cincuenta por ciento para humanidades, quedan 500 para ciencias, de estas la mitad para cualitativos, quedan 250 para experimentales o cuantitativos.

\footnotetext{
a. Biólogo, doctor en Ciencias Biológicas.
}

correo: raishiyama@yahoo.com

Correspondencia: Raúl Ishiyama Cervantes https://doi.org/10.37065/rem.v5i3.366 
Si fueran 10 universidades serían 2500 por año, si fueran 20 universidades serían 5000 por año, si fueran 50 universidades serían 12500 por año. Si todas se publicaran para ser difundidas, sería un inmenso aporte, situándonos como una potencia científica en Latinoamérica. Sin considerar las investigaciones que se realizan en forma independiente y en la industria. Si de este total después de sustentadas, 2500 son detectados como plagio, 10000 sigue siendo significativo.

Salvo excepciones, cada facultad de la misma universidad tiene su propio formato de tesis. Los formatos de las tesis no están de acuerdo con el formato del artículo científico, por lo que, si el autor desea publicarla en una revista requiere estructurarla como artículo. Para escribir la tesis en formato de artículo, se debe utilizar la tesis como si fuera el cuaderno de campo ${ }^{(2)}$, siguiendo el siguiente método sencillo permitirá que el contenido de la tesis pueda ser escrita como artículo para ser publicada. La información contenida en la tesis para hacerla como artículo se debe escribir en el siguiente orden:

$\begin{array}{lc}\text { Sección } & \begin{array}{c}\text { ocupa en el } \\ \text { artículo }\end{array} \\ \text { 01. Material y métodos. } & 06 \\ \text { 02. Resultados con tablas y figuras. } & 07 \\ \text { 03. Discusión. } & 08 \\ \text { 04. Introducción. } & 05 \\ \text { 05. Referencias bibliográficas. } & 10 \\ \text { 06. Resumen con palabras clave. } & 04 \\ \text { 07. Agradecimientos. } & 09 \\ \text { 08. Autor(es). } & 02 \\ \text { 09. Institución. } & 03 \\ \text { 10. Título. } & 01\end{array}$

A medida que se va imprimiendo cada sección, siguiendo el procedimiento del orden en la escritura del artículo en "La equivocada creencia que iniciarse en la investigación científica es un proceso complicado", publicado en esta revista ${ }^{(3)}$; en la parte superior se coloca el número que se encuentra entre paréntesis.

Cuando se termina, se ordena del 01 al 10 y se tiene la secuencia de la tesis como artículo. Una vez armado el artículo se debe revisar la sintaxis, "La palabra impresa es eterna”. Las revistas en la sección indicaciones para los autores presentan la secuencia de como se debe escribir el artículo experimental:

01. Título.

02. Autor(es).

03. Institución.
04. Resumen.

05. Introducción.

06. Material y métodos.

07. Resultados.

08. Discusión.

09. Agradecimientos.

10. Referencias bibliográficas.

La tesis le costó al graduando tiempo, dinero y esfuerzo, por lo que debe ser de conocimiento de la comunidad para ser utilizada por los pares. El artículo y la tesis son investigaciones, el primero con un número determinado de páginas por razones editoriales, se publica de inmediato para su difusión; la segunda no tiene límite de páginas, su finalidad es que el autor logre un grado académico, muy rara vez se publica como artículo. El artículo tiene un formato estándar; las tesis se hacen de acuerdo al formato de cada institución, muy pocas similar al artículo.

Esta propuesta es con el objetivo que las tesis sean difundidas como artículos, mediante este sencillo modelo.

Algunos investigadores trabajan con la idea de llegar a un estado top, una de las obligaciones del investigador es difundir los conocimientos, no para impresionar con base a una serie de definiciones, reglas y leyes. Figurar en Scopus u otra base datos es meritorio, más importante es tener en cuenta que el investigador trabaja en beneficio de la humanidad, no para su ego; salvo mejor parecer.

Ante el déficit de investigadores, es necesario que se restructure el semillero de investigadores, con cursos sencillos y prácticos que atraigan a los jóvenes hacia esta tarea ${ }^{(4)}$.

\section{REFERENCIAS BIBLIOGRÁFICAS}

01. Sunedu. Ley 30220. El Peruano. 2014-07-09. En: https://www.sunedu.gob. pe/wp-content/uploads/2017/04/Ley-universitaria-30220.pdf

02. Ishiyama R. Pautas para la publicación de artículos científicos. Lima: Universidad Peruana Cayetano Heredia; 2010. Disponible en: https://docplayer.es/39549119-Universidad-peruana-cayetano-heredia.html

03. Ishiyama R. La equivocada creencia que iniciarse en la investigación científica es un proceso complicado. Revista Experiencia en Medicina. 2018; 4(1): 33-35.

04. Ishiyama R. Los jóvenes y la investigación científica. Revista Experiencia en Medicina. 2019; 5(2): 101-102. 